\title{
Alterations in mood after changing to a low-fat diet
}

\author{
Anita S. Wells ${ }^{1} *$, Nicholas W. Read ${ }^{1}$, Jonathan D. E. Laugharne ${ }^{2}$ and N. S. Ahluwalia ${ }^{2}$ \\ ${ }^{1}$ Centre for Human Nutrition, University of Sheffield, Northern General Hospital, Herries Road, Sheffield S5 7AU, UK \\ ${ }^{2}$ University Department of Psychiatry, Northern General Hospital, Herries Road, Sheffield S5 7AU, UK
}

(Received 24 February 1997 - Revised 6 June 1997 - Accepted 14 July 1997)

\begin{abstract}
The effects on mood of reducing dietary fat while keeping the energy constant were examined in ten male and ten female healthy volunteers aged between 20 and 37 years. Each volunteer consumed a diet containing $41 \%$ energy as fat for 1 month. For the second month half of the subjects changed to a low-fat diet ( $25 \%$ energy from fat) and the remainder continued to eat the diet containing $41 \%$ energy from fat. Changes in mood and blood lipid concentrations were assessed before, during and at the end of the study. Profile of mood states (POMS) ratings of anger-hostility significantly increased in the intervention group after 1 month on the low-fat diet, while during the same period there was a slight decline in anger-hostility in the control subjects (group $F 6.72$; df 1,$14 ; P=0.021$ ). Tension-anxiety ratings declined in the control group consuming the higher fat diet but did not change in the group consuming the low-fat diet (group $F 6.34$; df 1,$14 ; P=0.025$ ). There was a decline in fasting concentrations of HDLcholesterol after the low-fat diet and a small increase in subjects consuming the medium-fat diet (group $F 4.96$; df 1,$12 ; P=0.046$ ), but no significant changes in concentrations of total serum cholesterol, LDL-cholesterol or triacylglycerol were observed. The results suggest that a change in dietary fat content from 41 to $25 \%$ energy may have adverse effects on mood. The alterations in mood appear to be unrelated to changes in fasting plasma cholesterol concentrations.
\end{abstract}

Mood: Fat intake: Anger: Tension: Depression

For the past decade health experts have recommended a reduction in the amount of fat in the British diet with the aim of lowering plasma cholesterol levels and thereby reducing mortality from ischaemic heart disease (Department of Health and Social Security, 1984; Department of Health, 1991, 1994). There are, however, suggestions that this policy may be associated with adverse behavioural and psychological effects. A meta-analysis of trials in which diet and drug regimens were used to lower cholesterol levels showed an association with a heightened incidence of fatal accidents, violent deaths and suicides (Muldoon et al. 1990). Other studies have noted associations between low levels of LDL-cholesterol and depression (Morgan et al. 1993; Brown et al. 1994) and between low serum cholesterol levels and increased suicide (Lindberg et al. 1992; Neaton et al. 1992). However, recent placebo controlled studies show that lowering plasma cholesterol concentrations using 3hydroxy-3-methylglutaryl coenzyme A (HMG-CoA) re- ductase inhibitors does not significantly influence mood or the prevalence of deaths from non-coronary causes (Kjekshus \& Pedersen, 1995; Shepherd et al. 1995; Sacks et al. 1996; Wardle et al. 1996). Thus, it could be that low cholesterol concentrations are simply a marker of a low dietary fat intake. Intervention studies in experimental animals have shown that contact aggression was significantly higher in monkeys fed on a 'prudent diet' (lowfat, low cholesterol, high carbohydrate ( $\mathrm{CHO})$ ) compared with those on a 'luxury diet', higher in fat and cholesterol and lower in CHO (Kaplan et al. 1991). Short-term studies in human subjects indicate that low-fat-high-CHO meals eaten in the morning make subjects feel more antagonistic and less friendly, contented, interested, sociable and outgoing in the $3 \mathrm{~h}$ after ingestion than isoenergetic high-fatlow-CHO meals (Smith et al. 1994a; Wells \& Read, 1996).

Few studies have investigated the longer term effects of low-fat diets on mood in healthy human volunteers.

\footnotetext{
Abbreviations: CHO, carbohydrate; HMG-CoA, 3-hydroxy-3-methylglutaryl coenzyme A; POMS, profile of mood states; TAG, triacylglycerol; TSC, total serum cholesterol.

*Corresponding author: Ms A.S. Wells, fax + $44(0) 114$ 2610112; email a.s.wells@sheffield.ac.uk
} 
Subjects participating in a 5-year heart disease prevention programme, who successfully changed to a lower-fat diet ( $<30 \%$ energy from fat, $1 \%$ fall in plasma cholesterol) reported a significantly greater decline in depression and hostility (measured by the Hopkins symptom checklist) at the end of the study than those who did not change their diet, and continued to eat a higher-fat diet (Weidner et al. 1992). However, as the subjects were repeatedly informed about the health risks of consuming a high-fat diet, it is hardly surprising that those who successfully changed their diet felt less depressed and hostile than those who failed (Carmody et al. 1986).

The aim of the present pilot study was to investigate whether there are adverse psychological effects of changing to a low-fat diet, by conducting a small but highly controlled intervention study in free-living healthy male and female adults.

\section{Methods}

\section{Subjects}

These were ten healthy male and ten healthy female volunteers aged $20-37$ years (mean age 26.6 years, mean BMI $23.4 \mathrm{~kg} / \mathrm{m}^{2}$ ) recruited from the Sheffield area by means of advertisements. Rigorous volunteer selection criteria (Table 1) minimized confounding variables likely to influence mood.

All volunteers gave their written informed consent for the study to be conducted. The protocol was approved by the ethics committee of the Northern General Hospital Trust.

\section{Table 1. Volunteer selection criteria}

\begin{tabular}{l} 
Inclusion \\
Non-smoker \\
Good health \\
Age $18-40$ years \\
BMI $20-31 \mathrm{~kg} / \mathrm{m}^{2}$ \\
Consume no more than 21 units of alcohol per week \\
Female subjects: a regular menstrual cycle of $26-33 \mathrm{~d}$ \\
Exclusion \\
History of cardiac, renal, or hepatic disorders \\
Previously received treatment for a psychiatric disorder (including \\
treatment by a general practitioner for complaints such as \\
depression, anxiety, and 'nerves') \\
Moderate or extreme pre-menstrual anxiety or depression \\
(Halbreich et al. 1982) \\
Likely to experience a stressful event during the months of the \\
study e.g. exams, buying a house, getting married, having an \\
operation \\
Pregnant or planning to become pregnant during the months of the \\
study \\
Actively trying to reduce body weight \\
History of drug or alcohol abuse \\
On medication (other than the oral contraceptive pill) \\
Normally consume a low-fat diet (less than $25 \%$ energy from fat) \\
(Yarnell et al. 1983) \\
Fasting plasma triacylglycerol concentration $>2.3$ mmol/l \\
Fasting total serum cholesterol concentration $>10$ mmol// \\
Depressed on entry to the study (assessed by psychiatrist) \\
\hline
\end{tabular}

\section{Procedure}

The effects of changing to a low-fat diet were assessed using a tightly controlled, balanced intervention study. All twenty subjects underwent an 'acclimatization' period during which they consumed a diet containing $41 \%$ food energy from fat for 1 month, a level similar to that contained in the average UK diet (Gregory et al. 1990). Female subjects started the study between days 6 and 13 of their menstrual cycle. For the second month subjects were divided into two groups. The intervention group changed to a low-fat diet ( $25 \%$ food energy from fat), slightly lower than current British guidelines (Department of Health and Social Security, 1984; Department of Health, 1991, 1994) while the control group remained on the $41 \%$ fat diet (Fig. 1). The investigation was carried out between January and April, and in order to control for changes in the weather and/or season, half of the male and half of the female subjects beginning the study during the same week were randomly put into each of the groups in a balanced design, planned before subjects started the study. At the beginning of the study, after 1 month and after 2 months, subjects visited the Centre for Human Nutrition, where mood was assessed (described later), body weight measured and fasting blood samples were taken to determine concentrations of LDL-cholesterol, HDL-cholesterol, triacylglycerol (TAG) and total serum cholesterol (TSC) (Fig. 1). Measures of food intake were collected immediately before and after the 2 month study by means of a $7 \mathrm{~d}$ weighed inventory using digital scales (Soehnle AG, Montlingen, Switzerland) and a post-diet questionnaire was completed at the end of the dietary intervention period.

\section{Diets}

The diets, which were supplied and delivered weekly to subjects' own homes were calculated and each item individually portioned in order to provide individual subjects with their estimated daily energy requirements (Department of Health, 1991). Subjects selected the meals they wanted from a list of at least sixty different meals made up of foods and dishes requiring minimal preparation, available at a typical British supermarket. They were asked to consume all the food provided but nothing extra, recording when they ate each meal and rating its palatability. Subjects consumed one breakfast, one lunch and snacks and one dinner each day. Subjects recorded any extra food that they ate and any items that they did not eat, signing that this information was true and correct. The mean macronutrient intakes for both groups during the intervention period are listed in Table 2. They were calculated using Foodbase V1.1 (The Institute of Brain Chemistry and Human Nutrition, Queen Elizabeth Hospital for Children, Hackney Road, London E2 8PS, UK). Where foods were not listed in the database (such as for some of the frozen pre-prepared meals), these were calculated using information from the manufacturers. Both diets were designed to be equally enjoyable, with the differences in fat subtly disguised (for example by using full-fat and reduced-fat versions of products such as spreads, mayonnaise, ice-cream and crisps). Ratings of fullness and hunger 


\begin{tabular}{|c|c|c|}
\hline $\mathbb{D}$ & MF & $\begin{array}{ll}\mathrm{LF} & \mathrm{DD}\end{array}$ \\
\hline
\end{tabular}

\begin{tabular}{|l|l|lll|}
\hline a & $\mathrm{MF}$ & $\mathrm{MF}$ & $\mathrm{D}$ & Control group \\
\hline
\end{tabular}

\begin{tabular}{ccccl} 
& $\oplus$ & $(-)$ & & \\
\hline 1 & 1 & 1 & 1 & \\
-1 & 0 & 4 & 8 & $\begin{array}{l}\text { Time from start } \\
\text { of the diets (weeks) }\end{array}$
\end{tabular}

Fig. 1. Schematic representation of the study protocol. MF, medium-fat diet ( $41 \%$ energy as fat); LF, low-fat diet ( $25 \%$ energy as fat); $\mathbf{Q}, 7 \mathrm{~d}$ dietary record; $\odot$, assessment of mood.

were completed before and after each meal on $1 \mathrm{~d}$ per week throughout the study.

\section{Control of confounding variables}

Subjects were requested to maintain a constant level of exercise throughout the study and to keep a diary of this. Subjects were requested to maintain a similar pattern of alcohol ingestion each week, recording what they drank. Heavy drinking bouts were forbidden.

\section{Assessments of mood}

Mood was assessed using the unipolar version of the profile of mood states (POMS) questionnaire, a sensitive measure of mood in normal healthy subjects (McNair et al. 1971), as well as by means of a range of techniques designed to measure mood in a more clinical context; the Montgomery and Asberg depression and rating scale (Montgomery \& Asberg, 1979), the Cook Medley hostility scale (Cook \& Medley, 1954), the general health questionnaire (GHQ-30; Goldberg \& Williams, 1988) and Beck's depression inventory (Beck et al. 1981). On their monthly visits to the Centre for Human Nutrition, subjects were asked to describe how they had felt over the previous month by completing the POMS questionnaire, the Cook Medley hostility scale, the general health questionnaire and Beck's depression inventory. Then a psychiatrist (J.L. or R.A.), unaware of the subject's diet, interviewed subjects in order to be able to give an assessment of their mood using the Montgomery and Asberg depression and rating scale. In this interview the psychiatrist also assessed whether any recent 'life' events (such as accidents, illness, distressing news) may have significantly influenced subjects' mood. This was so that the groups remained matched as well as possible.

Table 2. Mean daily macronutrient composition of the diets eaten during the intervention period

\begin{tabular}{|c|c|c|c|c|}
\hline & \multicolumn{2}{|c|}{$\begin{array}{l}\text { Medium-fat diet } \\
\qquad(n 9)\end{array}$} & \multicolumn{2}{|c|}{$\begin{array}{l}\text { Low-fat diet } \\
\quad(n 10)\end{array}$} \\
\hline & Mean & SD & Mean & SD \\
\hline Energy intake (kJ) & 10525 & 2581 & 10571 & 2128 \\
\hline $\begin{array}{l}\text { Fat (\% energy) } \\
\text { Saturated fatty acids (\% energy) } \\
\text { Cis-monounsaturated fatty acids (\% energy) } \\
\text { Cis-polyunsaturated fatty acids (\% energy) } \\
\text { Trans fatty acids ( } \% \text { energy) }\end{array}$ & $\begin{array}{r}41 \\
18 \cdot 1 \\
11.9 \\
7.9 \\
2.8\end{array}$ & $\begin{array}{l}0.1 \\
1.1 \\
0.8 \\
1.1 \\
0.5\end{array}$ & $\begin{array}{l}25 \\
11.8 \\
7.2 \\
3.9 \\
1.9\end{array}$ & $\begin{array}{l}0.6 \\
0.7 \\
0.8 \\
0.4 \\
0.3\end{array}$ \\
\hline $\begin{array}{l}\text { Carbohydrate (\% energy) } \\
\text { Starch (\% energy) } \\
\text { Sugars (\% energy) }\end{array}$ & $\begin{array}{l}46 \\
27 \\
19\end{array}$ & $\begin{array}{l}0.5 \\
0.8 \\
1.0\end{array}$ & $\begin{array}{l}61 \\
36 \\
25\end{array}$ & $\begin{array}{l}1 \cdot 3 \\
1.8 \\
2 \cdot 2\end{array}$ \\
\hline Protein (\% energy) & 13 & 0.5 & 14 & 0.7 \\
\hline Alcohol intake (units) & 1.3 & 0.9 & 1.5 & 0.8 \\
\hline
\end{tabular}




\section{Data analysis}

After examination of the distribution of the data, all mood variables (except vigour) were transformed using a $\log$ transformation (to reduce skewedness). Baseline measures collected on the first and second visits were examined using a Student's $t$ test to check that the control group and intervention groups were well-matched. ANOVA for repeated measures was used to compare the measures of body weight and habitual dietary fat intake with the grouping factors, being group and sex. Mean weekly diet palatability ratings were derived from the individual meal ratings, and were compared as described earlier except that the within-subject factors were time (1 or 2) and week $(1-4)$.

Data on mood and blood lipids collected after the intervention period were analysed using a one way ANOVA, with the measure taken just before the dietary intervention period as the covariate. The grouping factors were the group (intervention or control) and sex.

\section{Results}

All twenty subjects satisfactorily completed the study up to the final visit. However, as a result of the final interview, the psychiatrist excluded one of the control subjects from the study. This is because she was severely upset by the death of two close friends. For the HDL- and LDLcholesterol concentrations the ANOVA was performed on data from seventeen subjects as these measurements were mistakenly omitted for two of the subjects.

The subjects in both groups were similar in age, sex, weight, BMI, habitual diet, fasting lipid profile, marital status and education (Table 3). Examination of the mood measures collected on the first and second visits using a Student's $t$ test indicated that there were no significant differences in any of the mood measures between the two different groups. Throughout the investigation there were no significant differences in responses between male and female subjects. There were no significant changes in body weight in either the control group or the intervention group during the course of the study (weight at end of study; control group 72.8 (SD 15.8) $\mathrm{kg}$, intervention group 71.8 (SD 15.8) kg). Subjects reported no significant differences in palatability (mean palatability rating; medium-fat diet 3.80 (SEM 0.12), low-fat diet 3.89 (SEM 0.16)), or feelings of hunger or fullness between the two diets (mean hunger rating; medium fat diet 23.9 (SEM 3.8), low-fat diet 22.0 (SEM 2.9), mean fullness rating; medium-fat diet 74.4 (SEM 3.6), low-fat diet 76.1 (SEM 3.1)). There were no significant differences in the percentage of energy from fat in subjects' habitual diet between the intervention group and the control group before or after the study (Table 3).

\section{Effects on mood: profile of mood states questionnaire}

Anger-hostility. There was a significant main effect of group ( $F \quad 6.72 ;$ df 1,$14 ; P=0.021$ ). Anger-hostility increased in the intervention group after 1 month on the low-fat diet, while during the same period there was a slight decline in anger-hostility in the control subjects (Table 4, Fig. 2). Pre-planned pairwise comparisons indicated that there was no significant difference in ratings of angerhostility before the dietary intervention, but afterwards the ratings were significantly higher in the intervention group than the control group $(t 3 \cdot 1 ;$ df 1,$17 ; P=0.006)$.

Depression-dejection. Ratings of depression over the intervention period increased after 1 month on the low-fat diet and declined slightly in the control group (Table 4, Fig. 2). This effect of group just failed to reach statistical significance ( $F 3.95$; df 1,$14 ; P=0.067)$. This was mostly due to two of the intervention group reporting substantially greater depression-dejection ratings.

Tension-anxiety. Diet significantly affected feelings of tension-anxiety (group $F 6.34$; df 1,$14 ; P=0.025$ ). Tension-anxiety declined in the control group consuming the higher fat diet but did not change in the group consuming the low-fat diet (Table 4, Fig. 2). Pre-planned

Table 3. Baseline characteristics of the subjects

(Mean values and standard deviations)

\begin{tabular}{|c|c|c|c|c|}
\hline & \multicolumn{2}{|c|}{ Intervention group ( $n$ 10) } & \multicolumn{2}{|l|}{ Control group $(n 9)$} \\
\hline & Mean & SD & Mean & SD \\
\hline Age (years) & 26.0 & 4.2 & $27 \cdot 2$ & 5.3 \\
\hline Weight (kg) & 71.1 & $16 \cdot 0$ & 72.4 & 15.7 \\
\hline $\mathrm{BMI}\left(\mathrm{kg} / \mathrm{m}^{2}\right)$ & 23.5 & 3.2 & 23.3 & 2.8 \\
\hline Vegetarian & $4 / 10$ & & $3 / 9$ & \\
\hline Pre-study diet: \% energy from fat & 37 & 3.9 & 36 & $4 \cdot 2$ \\
\hline Post-study diet: $\%$ energy from fat & 39 & 4.2 & 35 & 3.6 \\
\hline Total serum cholesterol $(\mathrm{mmol} / \mathrm{l})$ & 4.53 & 0.66 & 4.23 & 0.42 \\
\hline LDL-cholesterol (mmol/l) & 2.55 & 0.76 & 2.28 & 0.49 \\
\hline HDL-cholesterol (mmol/f) & 1.42 & 0.37 & 1.49 & 0.46 \\
\hline Triacylglycerol $(\mathrm{mmol} / \mathrm{l})$ & 1.20 & 0.40 & 0.98 & 0.21 \\
\hline Number of years studied full-time after the age of 5 & 16.0 & 2.0 & 15.9 & $2 \cdot 1$ \\
\hline Highest level of education completed & 6 degree & & 7 degree & \\
\hline & 4 professional/technical & & 2 professional/technical & \\
\hline Sex & 5 male, 5 female & & 5 male, 4 female & \\
\hline Marital status & $\begin{array}{l}7 \text { single, } 3 \text { cohabiting } \\
\text { or married }\end{array}$ & & $\begin{array}{l}6 \text { single, } 3 \text { cohabiting } \\
\text { or married }\end{array}$ & \\
\hline
\end{tabular}


Table 4. Mood and clinical ratings of subjects before and after 1 month of receiving a low-fat diet (intervention group) and for a control group* (Mean values and standard errors of the mean)

\begin{tabular}{|c|c|c|c|c|c|c|c|c|c|c|}
\hline \multirow[b]{3}{*}{ Measure } & \multicolumn{4}{|c|}{ Intervention group $(n 10)$} & \multicolumn{4}{|c|}{ Control group ( $n 9)$} & \multirow{2}{*}{\multicolumn{2}{|c|}{$\begin{array}{l}\text { Significance o } \\
\text { group effects } \dagger \\
\text { (df } 1,14)\end{array}$}} \\
\hline & \multicolumn{2}{|c|}{ Before } & \multicolumn{2}{|c|}{ After } & \multicolumn{2}{|c|}{ Before } & \multicolumn{2}{|c|}{ After } & & \\
\hline & Mean & SEM & Mean & SEM & Mean & SEM & Mean & SEM & $F$ & $P$ \\
\hline \multicolumn{11}{|l|}{ Profile of Mood States Questionnaire (McNair et al. 1971) } \\
\hline Anger-hostility & 1.3 & 0.5 & 3.4 & 1.3 & 0.6 & 0.3 & 0.3 & 0.2 & 6.72 & 0.021 \\
\hline Depression-dejection & 0.2 & 0.2 & 1.4 & 1.0 & 0.2 & 0.2 & 0.0 & 0.0 & 3.95 & 0.067 \\
\hline Tension-anxiety & 3.6 & 0.9 & 3.8 & 1.2 & 4.2 & 1.1 & 1.8 & 0.4 & $6 \cdot 34$ & 0.025 \\
\hline Confusion-bewilderment & 3.3 & 0.9 & 2.5 & 0.9 & 2.7 & 0.6 & $2 \cdot 2$ & 0.4 & $<1$ & 0.416 \\
\hline Vigour-activity & 14.3 & $2 \cdot 2$ & 14.3 & 2.7 & 20.0 & 3.0 & 17.8 & 2.6 & $<1$ & 0.982 \\
\hline Fatigue-inertia & $4 \cdot 6$ & 1.9 & 3.1 & $1 \cdot 0$ & 1.4 & 1.0 & 1.1 & 0.6 & 1.20 & 0.292 \\
\hline \multicolumn{11}{|l|}{ Clinical measures } \\
\hline Depression and Rating Scale (Montgomery \& Asberg, 1979) & 0.6 & 0.3 & 0.7 & 0.3 & 0.2 & 0.2 & 0.4 & 0.3 & $<1$ & 0.728 \\
\hline Cook-Medley Hostility Scale (Cook \& Medley, 1954) & 13.3 & 1.5 & $15 \cdot 8$ & 1.9 & $12 \cdot 1$ & 2.0 & 13.5 & 2.7 & $<1$ & 0.594 \\
\hline General Health Questionnaire (Goldberg \& Williams, 1988) & 0.6 & 0.3 & 2.7 & 1.3 & 0.3 & 0.2 & 0.7 & 0.4 & 1.21 & 0.290 \\
\hline Beck's Depression Inventory (Beck et al. 1981) & 1.6 & 0.6 & 1.7 & 0.9 & 0.4 & 0.3 & 0.8 & 0.4 & $<1$ & 0.523 \\
\hline
\end{tabular}

- For details of subjects and procedures, see Tables 1 and 2 and pp. 24-26.

$\dagger$ One-way ANOVA.

pairwise comparisons indicated that there was no significant difference in ratings of tension-anxiety either before or after the dietary intervention between the intervention and control groups.

Confusion-bewilderment, vigour-activity and fatigueinertia. There were no significant differences in any of these ratings between the control and intervention groups before or after the intervention (Table 4).

\section{Effects on mood: other questionnaires and ratings}

There were no significant changes in any of the measures between the two groups. No subject came close to the cutoff point for clinical depression at any stage in the study (Table 4).

\section{Blood samples}

There was a decline in HDL-cholesterol concentrations after 1 month on the low-fat diet, (group $F$ 4.96; df 1,12; $P=0.046$ ). There were no significant changes in TSC, LDL-cholesterol or TAG concentrations in subjects consuming the low-fat diet (Table 5).

\section{Post-diet questionnaire}

A greater proportion of the intervention group thought that their diet had changed compared with the control subjects (nine out of ten $v$. five out of nine); however only three out of the ten subjects in the intervention group were aware that the change had been to a lower fat diet. Six of the intervention group thought that their mood had been influenced by their diet, compared with none of the control group. The changes described indicated that subjects felt more moody, irritable, annoyed and dissatisfied while consuming the low-fat diet. There were no differences in the changes in anger and depression in the group of subjects
Table 5. Changes in fasting plasma lipid concentrations $(\mathrm{mmol} / \mathrm{l})$ for subjects receiving a low-fat diet for 1 month (Intervention group) and for a control group*

(Mean values and standard deviations)

\begin{tabular}{|c|c|c|c|c|c|c|}
\hline \multirow[b]{2}{*}{ Blood lipid fraction } & \multicolumn{2}{|c|}{$\begin{array}{l}\text { Intervention } \\
\text { group }\end{array}$} & \multicolumn{2}{|c|}{ Control group } & \multicolumn{2}{|c|}{$\begin{array}{l}\text { Significance of } \\
\text { group effects } \dagger \\
\text { (df } 1,12 \text { ) }\end{array}$} \\
\hline & Mean & SD & Mean & so & $F$ & $P$ \\
\hline $\begin{array}{l}\text { HDL-cholesterol } \\
\text { TSC } \\
\text { LDL cholesterol } \\
\text { TAG }\end{array}$ & $\begin{array}{r}-0.12 \\
-0.12 \\
-0.01 \\
0.05\end{array}$ & $\begin{array}{l}0.04 \\
0.06 \\
0.09 \\
0.10\end{array}$ & $\begin{array}{r}0.05 \\
0.01 \\
-0.05 \\
-0.16\end{array}$ & $\begin{array}{l}0.05 \\
0.14 \\
0.11 \\
0.14\end{array}$ & $\begin{aligned} & 4.96 \\
< & 1 \\
< & 1 \\
& 3.12\end{aligned}$ & $\begin{array}{l}0.046 \\
0.933 \\
0.379 \\
0.099\end{array}$ \\
\hline
\end{tabular}

"For details of subjects and procedures, see Tables 1 and 2 and pp. 24-26. †One-way ANOVA.

who thought that their mood had been influenced by their diet, and those who did not.

\section{Discussion}

The results of this study indicate that a change of diet for 1 month from an average UK medium-fat diet ( $41 \%$ energy from fat) to one that is slightly lower in fat than current British guidelines ( $25 \%$ energy from fat) altered the mood of ten healthy volunteers. Ratings of anger-hostility (POMS) increased in subjects who changed to a low-fat diet compared with those who remained on the higher fat diet. Depression-dejection (POMS) also tended to increase in some subjects after they changed to a low-fat diet, although overall this trend just failed to be statistically significant. Feelings of tension and anxiety (POMS) declined throughout the study while subjects consumed the medium-fat diet, but not in subjects eating the low-fat diet, suggesting that effects of the low-fat diet masked the usual decline in feelings of tension and anxiety as the study progressed. The data from the present study are consistent with the previous observation that human volunteers felt 

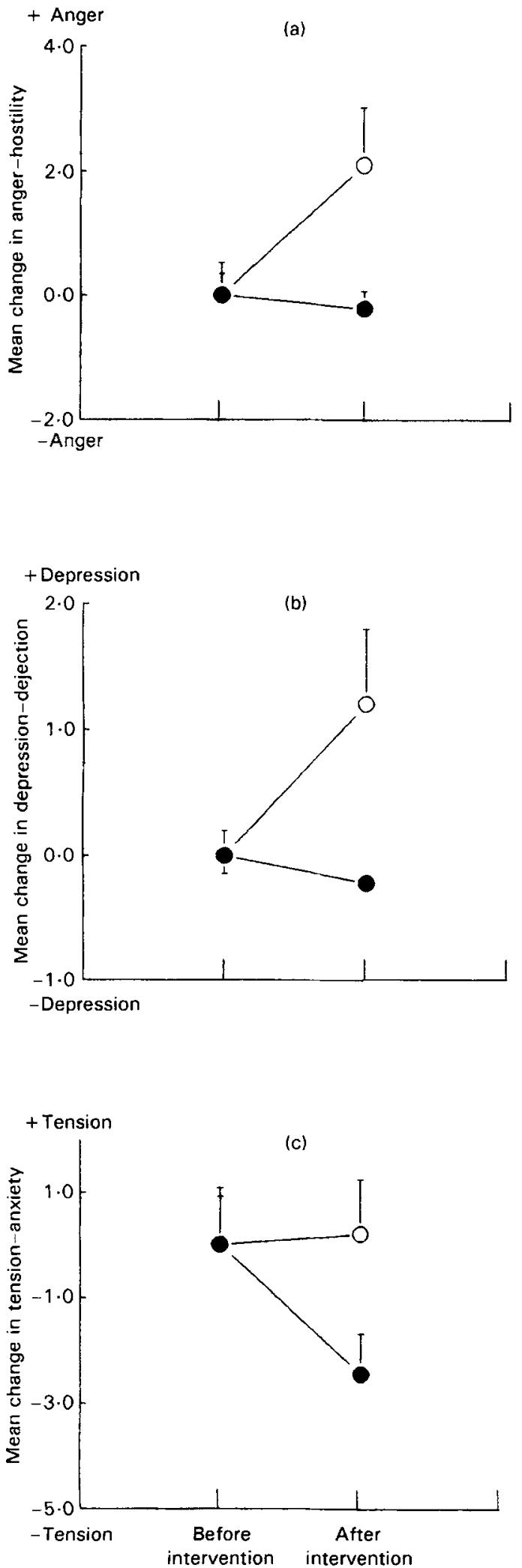

Fig. 2. Ratings of (a) anger-hostility, (b) depression-dejection and (c) tension-anxiety from the Profile of Mood States Questionnaire for subjects before and after the intervention period. (O), subjects $(n 9)$ who received low-fat diet; $(\Theta)$, subjects who received the control diet $(n 10)$. Values are means with their standard errors represented by vertical bars. Significance of group effects by one-way ANOVA were: (a) $P=0.021$, (b) $P=0.067$ and (c) $P=0.025$. more relaxed and friendly and less tense and antagonistic following high-fat meals than they did after low-fat meals (Smith et al. 1994b; Wells \& Read, 1996). Similarly, the difference in feelings of anger and hostility between the groups in the present study supports recent reports that monkeys (Macaca fascicularis) are more aggressive and spend less time in passive body contact or within touching distance of each other when they are fed on a low-fat diet than they do when they are fed on a high-fat diet (Kaplan $e t$ al. 1996).

As this was a pilot study, we chose to investigate only twenty volunteers, under conditions that were very tightly controlled, rather than conduct observations in a much larger number in a more natural context. A parallel control group of subjects were closely matched for age, sex, mood and plasma lipid concentrations and there were no significant differences in ratings of palatability, hunger and satiety measures between the two diets. The extremely wide choice of meals prevented monotony and maintained volunteer motivation and compliance at a high level throughout the study. Providing subjects with all their food meant that the dietary manipulation did not depend on the subjects' ability or keenness to follow dietary guidelines.

Although only three of the ten measurements of mood tended to show differences, we think that it is unlikely that these results reflect a type 1 error. The changes that were observed after the low-fat diet not only supported previous research, but were also similar in nature. Anger, hostility, depression, dejection, anxiety and tension are all negative mood states associated with increased arousal. Moreover it is not surprising that there were no changes on the 'clinical' scales such as Beck's depression index and the general health questionnaire as these are designed to identify psychiatric illness and are not sensitive to relatively small changes in healthy individuals. The subjects taking part in the study were a psychologically robust group who had never previously suffered from depression or anxiety, and who were not going through any 'stressful' events during the study. The alterations in mood observed in the present study may have been greater if subjects were feeling more stressed or were more susceptible to mental illness.

The decline in HDL-cholesterol concentrations after the low-fat diet indicates that the subjects consumed the diets supplied (Coulston et al. 1983; Grundy 1986). It is not surprising that we observed no significant changes in the fasting concentrations of TSC and LDL-cholesterol in the present study, since Nelson et al. (1995) recently reported that there were no significant changes in TSC or LDLcholesterol $50 \mathrm{~d}$ after subjects changed from a diet containing $39 \%$ energy from fat to one containing $22 \%$ energy from fat of similar fatty acid composition. Also, subjects' serum cholesterol concentrations were fairly low before the change to a low-fat diet. The intakes of saturated and trans fatty acids (in terms of percentage of food energy) in the low-fat diet were similar to current recommendations, and the medium-fat diet contained similar levels of saturated and trans fatty acids to those found in the average British diet (Ministry of Agriculture, Fisheries and Food, 1994). 
Subjects rated the palatability of the diets as similar, and two-thirds of those consuming the low-fat diet could not identify it as such. This suggests that the changes in mood were mediated via physiological mechanisms. Since fasting concentrations of TSC and LDL-cholesterol did not change, candidate physiological mechanisms might include changing cholecystokinin and serotonin concentrations. Cholecystokinin is known to influence a variety of behaviours including satiety and sedation (Fara et al. 1969; Smith et al. 1974), and increasing habitual dietary fat intake increases plasma cholecystokinin concentrations after a standard meal (French et al. 1995). Cholecystokinin concentrations affect serotonin activity in the brain (Stallone et al. 1989), and serotonin receptor sensitivity declines when monkeys are fed on a low-fat diet (Muldoon et al. 1992). Furthermore, low serotoninergic activity is associated with aggressive and suicidal behaviour (Coccaro et al. 1989; Moss et al. 1990).

In conclusion, changing to a slightly lower-fat diet than recommended may have adverse effects on the mood of healthy individuals during the first month. These changes do not appear to be related to changes in fasting cholesterol concentrations. Further studies are needed with longer dietary intervention periods to assess the time course of the effects of dietary change, in larger and more varied populations including those vulnerable to mental illness and those undergoing stressful events.

\section{Acknowledgements}

We would like to thank Dr T. A. Gray and the Department of Clinical Chemistry at the Northern General Hospital for analysing the blood samples. This research was funded by the University of Sheffield, with a contribution from the Kellogg's Company of Great Britain.

\section{References}

Beck AT, Ward CH, Mendelson M, Mock J \& Erbaugh J (1981) An inventory for measuring depression. Archives of General Psychiatry 4, 561-571.

Brown SL, Salive ME, Harris TB, Simonsick EM \& Guralnik JM (1994) Low cholesterol concentrations and severe depressive symptoms in elderly people. British Medical Joumal 308, 1328-1332.

Carmody TP, Istovan J, Matarazzo JD, Connor S \& Connor WE (1986) Applications of social learning theory in the promotion of heart-healthy diets, the Family Heart Study dietary intervention model. Health Education Research 1, 13-27.

Coccaro EF, Siever LJ, Klar HM, Maurer G, Cochrane K, Cooper TB, Mohs RC \& Davis KL (1989) Serotonergic studies in patients with affective and personality disorders. Archives of General Psychiatry 46, 587-599.

Cook WW \& Medley DM (1954) Proposed hostility and pharisaic-virtue scales for the MMPI. Journal of Applied Psychology 38, 414-418.

Coulston AM, Liu GC \& Reaven GM (1983) Plasma glucose, insulin and lipid responses to high-carbohydrate low-fat diets in normal humans. Metabolism 32, 52-56.

Department of Health (1991) Dietary Reference Values for Food Energy and Nutrients for the United Kingdom. Report on Health and Social Subjects no. 41. London: H. M. Stationery Office.
Department of Health (1994) Nutritional Aspects of Cardiovascular Disease. Report on Health and Social Subjects no. 46. London: H. M. Stationery Office.

Department of Health and Social Security (1984) Diet and Cardiovascular Disease. Report on Health and Social Subjects no. 28. London: H. M. Stationery Office.

Fara JW, Rubinstein EH \& Sonnenschein RR (1969) Visceral and behavioural responses to intraduodenal fat. Science 166, 110111.

French SJ, Murray B, Rumsey RDE, Fadzlin R \& Read NW (1995) Adaptation to high-fat diets: effects on eating behaviour and plasma cholecystokinin. British Journal of Nutrition 73, 179-189.

Goldberg D \& Williams P (1988) A User's Guide to the General Health Questionnaire. Windsor: NFER-Nelson.

Gregory J, Foster K, Tyler H \& Wiseman M (1990) The Dietary and Nutritional Survey of British Adults. London: H. M. Stationery Office.

Grundy SM (1986) Comparison of monounsaturated fatty acids and carbohydrates for lowering plasma cholesterol. The New England Journal of Medicine 314, 745-748.

Halbreich U, Endicott J \& Schacht S (1982) Premenstrual syndromes, a new instrument for their assessment. Journal of Psychiatric Evaluation and Treatment 4, 161-164.

Kaplan JR, Fontenot MB, Manuck SB \& Muldoon MF (1996) Influence of dietary lipids on agonistic and affiliative behaviour in Macaca fascicularis. American Journal of Primatology 38, 333-347.

Kaplan JR, Manuck SB \& Shively C (1991) The effects of fat and cholesterol on social behaviour in monkeys. Psychosomatic Medicine 53, 634-642.

Kjekshus J \& Pedersen TR (1995) Reducing the risk of coronary events: evidence from the Scandinavian simvastatin survival study (4S). American Journal of Cardiology 76, 64C-68C.

Lindberg G, Rastam L, Gullberg B \& Eklund GA (1992) Low serum cholesterol concentration and short term mortality from injuries in men and women. British Medical Journal 35, 227279.

McNair PM, Lorr M \& Dropplemen LF (1971) Profile of Mood States Manual. San Diego, CA: Education and Industrial Testing Service.

Ministry of Agriculture, Fisheries and Food (1994) The Dietary and Nutritional Survey of British Adults: Further Analysis. London: H. M. Stationery Office.

Montgomery SA \& Asberg M (1979) A new depression scale designed to be sensitive to change. British Joumal of Psychiatry 134, 382-389.

Morgan RE, Palinkas LA, Barrett-Connor EL \& Wingard DL (1993) Plasma cholesterol and depressive symptoms in older men. Lancet 341, 75-79.

Moss HB, Yao JK \& Panzak GL (1990) Serotonergic responsivity and behavioural dimensions in antisocial personality disorder with substance abuse. Biological Psychiatry 28, 325338.

Muldoon MF, Kaplan JR, Manuck SB \& Mann JJ (1992) Effects of a low-fat diet on brain serotonergic responsivity in cynomolgus monkeys. Biological Psychiatry 31, 739742 .

Muldoon MF, Manuck SB \& Matthews KA (1990) Lowering cholesterol concentrations and mortality: a quantitative review of primary prevention trials. British Medical Journal 301, 309314.

Neaton JD, Blackburn H, Jacobs D, Kuller L, Lee D-J, Sherwin R, Shih J, Stamler J \& Wentworth D (1992) Serum cholesterol level and mortality findings for men screened in the Multiple Risk Factor Intervention Trial. Archives of Internal Medicine 152, $1490-1500$ 
Nelson GJ, Schmidt PC \& Kelley DS (1995) Low-fat diets do not lower plasma cholesterol levels in healthy men compared to high-fat diets with similar fatty acid composition at constant caloric intake. Lipids 30, 969-976.

Sacks FM, Pfeffer MA, Moye LA, Rouleau JL, Rutherford JD, Cole TG, Brown L, Warnica JW, Arnold JMO, Wun CC, Davis BR \& Braunwald E (1996) The effect of pravastatin on coronary events after myocardial infarction in patients with average cholesterol levels. New England Joumal of Medicine 335, 1001-1009.

Shepherd J, Cobbe S, Ford I, Isles, CG, Lorimer AR, Macfarlane PW, McKillop JH \& Packard CJ (1995) Prevention of coronary heart disease with pravastatin in men with hypercholesterolemia. New England Journal of Medicine 333, 1301-1307.

Smith A, Kendrick A, Maben A \& Salmon J (1994a) Effects of breakfast and caffeine on cognitive performance, mood and cardiovascular functioning. Appetite 22, 39-55.

Smith A, Kendrick A, Maben A \& Salmon J (1994b) Effects of fat content, weight, and acceptability of the meal on postlunch changes in mood, performance and cardiovascular function. Physiology and Behavior 55, 417-422.
Smith GP, Gibbs J \& Young RC (1974) Cholecystokinin and intestinal satiety in the rat. Federation Proceedings 35, 11461149.

Stallone D, Nicolaidis S, \& Gibbs J (1989) Cholecystokinininduced anorexia depends on serotoninergic function. American Journal of Physiology 256, R1138-R1141.

Wardle J, Armitage J, Collins R, Wallendszuz K, Keech A \& Lawson A (1996) Randomised placebo controlled trial of effect on mood of lowering cholesterol concentration. British Medical Journal 313, 75-78.

Weidner G, Connor SL, Hollis JF \& Connor, WE (1992) Improvements in hostility and depression in relation to dietary change and cholesterol lowering. Annals of Internal Medicine 117, 820-823.

Wells AS \& Read NW (1996) Influences of fat, energy and time of day on mood and performance. Physiology and Behavior 59, 1069-1076.

Yarnell JWG, Fehily AM, Milbank JE, Sweetnam PM \& Walker CL (1983) A short questionnaire for use in epidemiological surveys: comparison with weighed dietary records. Human Nutrition: Applied Nutrition 37A, 103-112. 